\title{
Experimental Study of Pool Nucleate Boiling Heat Transfer Characteristics of Lithium Bromide Solution with Additives
}

\author{
Y.F. GENG \& X.N. SONG \\ School of Energy and Power Engineering, Jiangsu University, Zhenjiang,China
}

\begin{abstract}
KEYWORDS: Additive; Lithium Bromide Solution; Surface Tension; Nucleate Pool Boiling ABSTRACT: The pool nucleate boiling heat transfer characteristics of $10 \%, 20 \%$ and $30 \%$ lithium bromide solution was studied in the paper with Polyethylene Glycol Octylphenol Ether as an additive. The results showed that the additive can significantly reduce the surface tension of lithium bromide solution and different concentrations of the solution have its own CMC. The additive can enhance boiling heat transfer. The extreme characteristic strengthening effect was shown. The optimum concentration of heat transfer enhancement was about at CMC of the corresponding concentration of lithium bromide solution. With the improving of lithium bromide solution concentration, the additive effect of heat transfer enhancement was slowing and this trend tends to gradually decrease.
\end{abstract}

\section{INTRODUCTION}

Lithium bromide $(\mathrm{LiBr})$ solution is widely used in the absorption refrigeration fields because of its strong water absorption. Lithium bromide absorption chillers use water as refrigerant. It is environmental protection, and can be driven by low-grade heat source, and has great potential in the use of energy-saving and environmental protection ${ }^{[1-2]}$. However, the unit deeds high degree of vacuum, the solution is easy to crystallize and low heat transfer coefficient and other disadvantages. So looking for additive which can effectively improve the heat transfer and characteristics of lithium bromide solution is an effective way to solve the disadvantages.

Current research on pool boiling heat transfer of lithium bromide solution are mainly concentrated in vacuum conditions ${ }^{[3]}$, high concentration ${ }^{[4-5]}$ area and nano-fluid based ${ }^{[6]}$. The research on the atmospheric pressure and other types of additives are less studied. Therefore, this article choose $20 \% \mathrm{LiBr}$ solution to study the regular its boiling heat transfer at atmospheric pressure by the addition of polyethylene glycol octylphenyl ether (Triton X-100), which can be a study reference for the following studies.

\section{Experimental Design}

\section{Experimental System}

Experimental system consists of a boiling vessel, condensing system, heating system and data acquisition system, as shown in Figure 1.

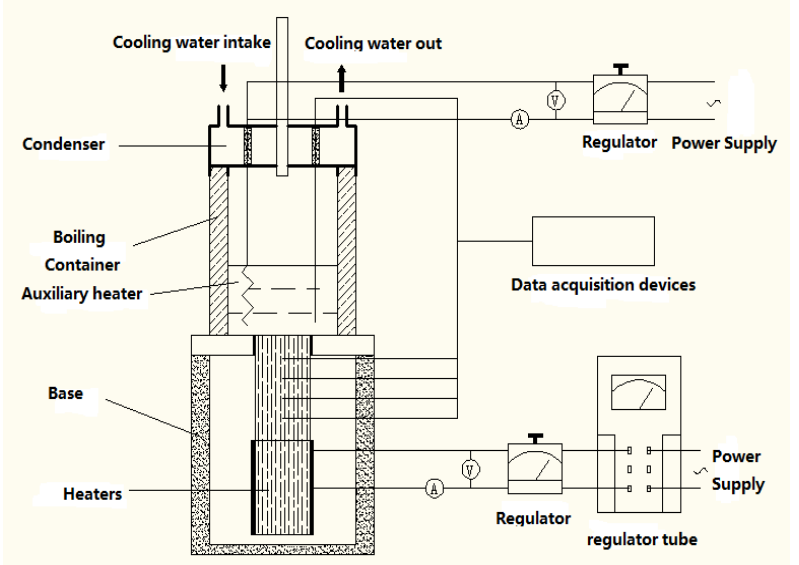

Figure 1. Schematic diagram of the experimental devices 


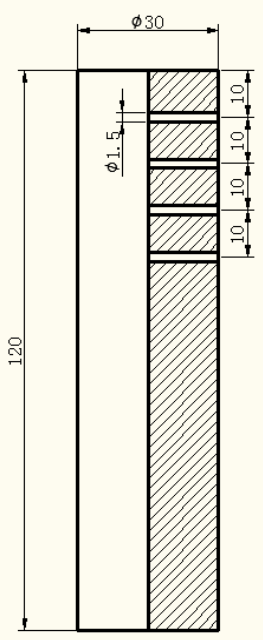

Figure 2. Thermocouple distribution

Boiling vessel is made of tempered glass. Then an upper portion of the vent tube, through the top surface of the condenser and vented to the atmosphere, in order to maintain atmospheric pressure. The condenser condensates steam in order to maintain stable concentration. Heating system made of copper column which is $150 \mathrm{~mm}$ long, $30 \mathrm{~mm}$ in diameter. Electric heating coil is wound in its bottom and is connected to a voltmeter, ammeter and voltage regulator. $0.2 \mathrm{~mm}$ thick of solid grease is laid between the heating coil and copper pillar to enhance the heat exchange and insulation. The end face of copper column was the heating surface. Four holes of $1.5 \mathrm{~mm}$ diameter were opened on the side face and insert four accuracy of $\pm 0.1{ }^{\circ} \mathrm{C}$ of K-type thermocouples to the center line of copper column, using to measure the temperature to calculate the temperature of the heating surface and heat flux, as shown in Figure 2. The data acquisition was the TC1008 multi-channel temperature measuring instrument. The whole system is strictly insulated by silicate insulation material.

\section{Experimental method}

Polyethylene glycol octylphenyl ether (Triton X-100) was chosen as additive and one water-lithium bromide (AR) as drug.

The relationship between lithium bromide and water was:

$\xi=\frac{86.85 m_{1}}{18.01 m_{1}+104.86 m_{2}}$

Where $\mathrm{m}_{1}$ was the mass of one water-lithium bromide, $\mathrm{g} ; \mathrm{m}_{2}$ was the mass of deionized water, $\mathrm{g}$; The surface tension of $\mathrm{LiBr}$ solution was measured by JYW-200B micro-controlled automatic interfacial tension with an accuracy of $0.1 \mathrm{mN} / \mathrm{m}$, at condition of $25 \pm 0.5^{\circ} \mathrm{C}$. Each sample was measured three times and taking average value. To avoid boiling lag effect, the test was taken by the way of reducing heating flux mode.

\section{Data Processing}

The temperature of heating surface was calculated by the fitting of the temperature of each measuring point with Matlab. The fitting function was quadratic function:

$T=A x^{2}+B x+c$

So $\mathrm{x}=0$, the heating surface temperature will be drawn:

$$
T_{w}=c
$$

The heating flux:

$$
q=-\left.\lambda \frac{d T}{d x}\right|_{x=0}=-\lambda B
$$


Where $\lambda$ was the thermal conductivity of copper, $401 \mathrm{~W} / \mathrm{m} \cdot \mathrm{K}$; Heat transfer coefficient:

$$
h=\frac{q}{T_{w}-T_{\text {sat }}}
$$

Where q was the heat flux, $\mathrm{W} / \mathrm{m} \cdot \mathrm{K} ; \mathrm{T}_{\mathrm{w}}$ was the temperature of heating surface, ${ }^{\circ} \mathrm{C}$; $\mathrm{T}_{\text {sat }}$ was the solution boiling temperature, ${ }^{\circ} \mathrm{C}$.

According to the transfer analysis method of Moffat ${ }^{[8]}$, the relative error of nucleate pool boiling heat transfer coefficient is:

$$
\frac{\Delta h}{h}=\sqrt{\left(\frac{\Delta q}{q}\right)^{2}+\left(\frac{\Delta T_{w}}{T_{w}-T_{\text {sat }}}\right)^{2}+\left(\frac{\Delta T_{\text {sat }}}{T_{w}-T_{\text {sat }}}\right)^{2}}
$$

The relative error of nucleate pool boiling heat transfer coefficient at experimental conditions can be obtained within $10 \%$.

\section{RESULTS AND DISCUSSION}

\section{Surface Tension}

Surface tension is considered as an important factor in boiling. Triton X-100 can reduce the surface tension of the solution ${ }^{[9]}$, affect bubble's formation and detachment and thereby influence the boiling heat transfer of solution ${ }^{[10]}$. When many scholars analyzing the boiling heat transfer of the salt solution, the focuses of the physical properties are on the surface tension change ${ }^{[11-12]}$. The measurement results of $\mathrm{LiBr}$ surface tension with Triton X-100 are shown in the figure 3.

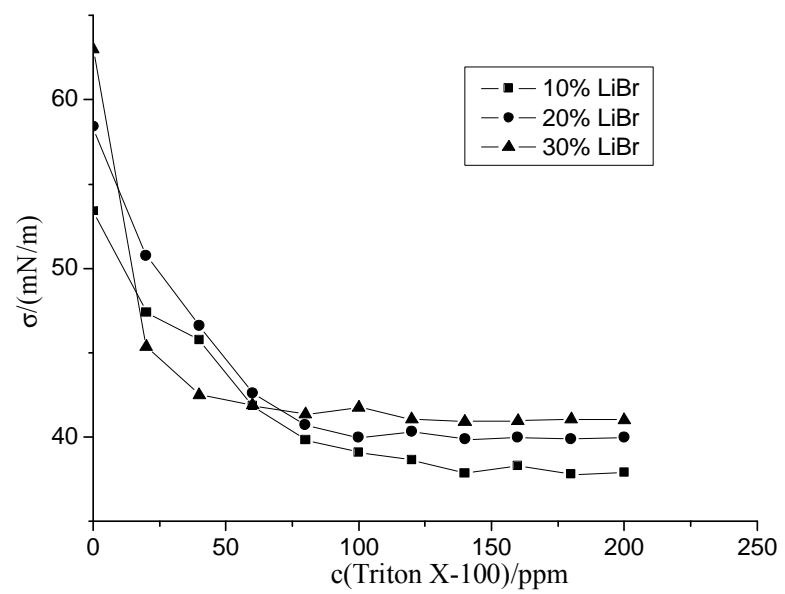

Figure 3. Relationship between surface tension and additive

From Figure 3 we can find little amount of additive can significantly reduce the surface tension of $\mathrm{LiBr}$ solution. At lower additive concentration, the surface tension of LiBr solution decreases rapidly with increasing concentration of additive. The downward trend decreases gradually and reaches a stable value. This concentration of the additive is the critical micelle concentration (CMC) of the corresponding $\mathrm{LiBr}$ solution. The $\mathrm{CMC}$ of $20 \% \mathrm{LiBr}$ solution is about $100 \mathrm{ppm}$.

\section{Boiling Heat Transfer}

The boiling heat transfer curves of LiBr solution with surfactant are shown in the figures 4-9. 


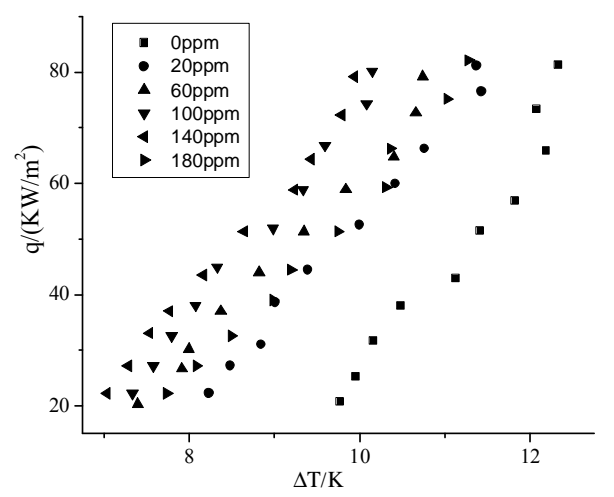

Figure 4. Nucleate boiling curves of $10 \% \mathrm{LiBr}$ solution

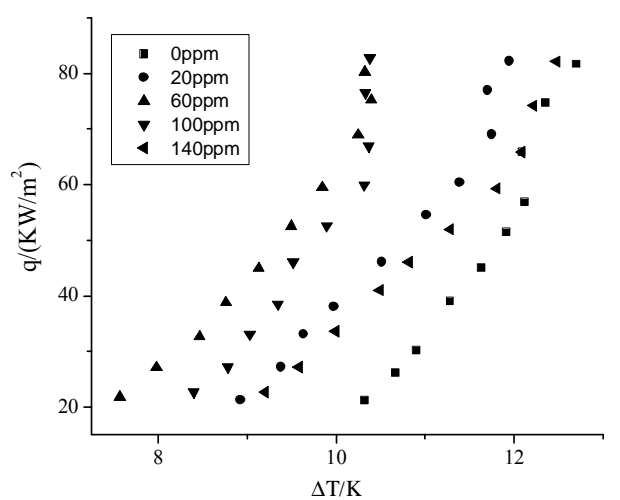

Figure 5. Nucleate boiling curves of $20 \% \mathrm{LiBr}$ solution

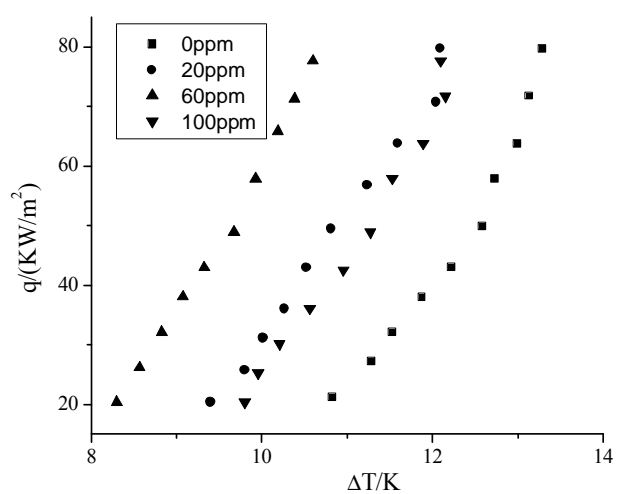

Figure 6. Nucleate boiling curves of $30 \% \mathrm{LiBr}$ solution

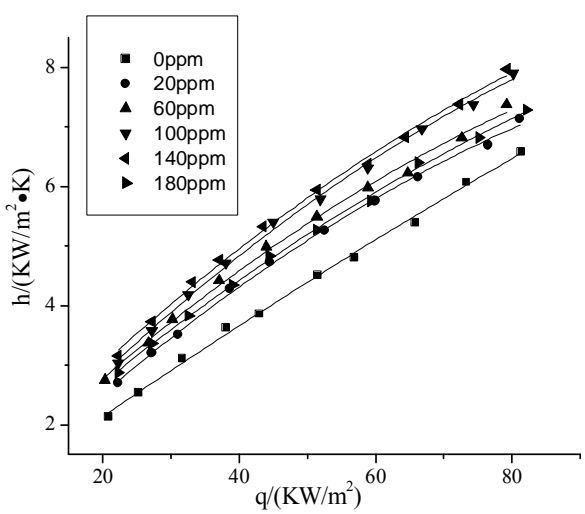

Figure 7. Pool boiling heat transfer coefficients of $10 \% \mathrm{LiBr}$ solutions 


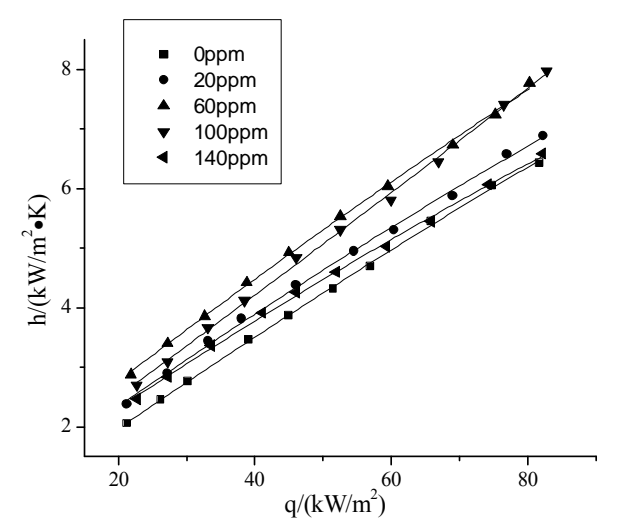

Figure 8 . Pool boiling heat transfer coefficients of $20 \% \mathrm{LiBr}$ solutions

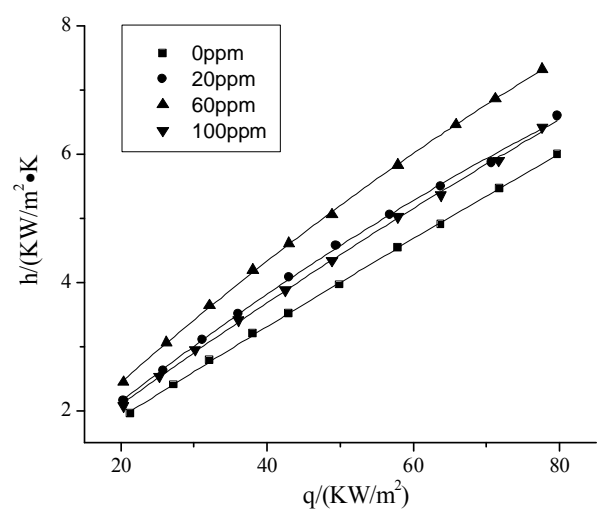

Figure 9. Pool boiling heat transfer coefficients of $30 \% \mathrm{LiBr}$ solutions

From figures 4-6, we can find that with the gradually improving of additive concentration, $\mathrm{LiBr}$ solution boiling curve gradually shifted to the left, showing a trend of strengthening. But when the additive concentration continues to increase, the boiling heat transfer curve shifts to the right, and shows a trend of weakening. Thus, although adding Triton X-100 into LiBr solution can enhance its boiling heat transfer, but it's strengthening effect exhibits extreme value characteristics, its optimal concentration of Triton X-100 is around its CMC. From figures 7-9, we can see that boiling heat transfer coefficients are not all the maximum at CMC. Therefore the relationship between the best effect of heat transfer and CMC needs to be further studied.

From the perspective of surface tension, it can be explained like this: The accumulation of additive at gas-liquid interface reduces the surface tension. Then the bubble generation energy reduces, detachment and cracking frequency increases and the diameter reduces. So the additive can strengthen the solution boiling heat transfer. When the surfactant concentration increased to its $\mathrm{CMC}$, the gas-liquid interfacial tension dropped to the lowest and the bubble diameter down to a minimum. But when the concentration is further improved, the gas-liquid interfacial tension is no longer decreased and the diameter of the bubbles is no longer reduced. At the same time, large number of additives in solution form micelles, which results in deterioration of the solid-liquid interface wettability and increase the difficulty of bubble creation. All those reasons result in the deterioration of boiling heat transfer.

In addition, at the best point of heat transfer, the heat transfer efficient of $10 \% \mathrm{LiBr}$ solution increases about $34 \%, 20 \%$ lithium bromide solution is about $29 \%$ and $30 \%$ lithium bromide solution is about $27 \%$. Accordingly, with the improving of lithium bromide solution concentration, the effect of additive is slowing down and the slowdown trend is gradually decreasing. The reason is that with the increasing of $\mathrm{LiBr}$ solution concentration, the surface tension of gas-liquid interface increases significantly, the wettability of solid-liquid interface deteriorated. Although additive reduce the surface tension, it still at a high value. All those reasons above affect the formation, detachment and rupture of bubbles. 


\section{Conclusion}

1) The additive can significantly reduce the surface tension of lithium bromide solution and different concentrations of the solution have its own CMC. At lower additive concentration, the surface tension of $\mathrm{LiBr}$ solution decreases rapidly with increasing concentration of additive. The downward trend decreases gradually and reaches a stable value.

2) The additive can enhance boiling heat transfer. The strengthening effect exhibits extreme value characteristics, its optimal concentration of Triton X-100 is around its CMC. The relationship between the best effect of heat transfer and $\mathrm{CMC}$ needs to be further studied.

3) With the improving of $\mathrm{LiBr}$ solution concentration, the additive effect of heat transfer enhancement was slowing and this trend tends to gradually decrease.

\section{Reference}

[1]J. D. Marcos, M. Izquierdo, R. Lizarte. Experimental boiling heat transfer coefficients in the high temperature generator of a double effect absorption machine for the lithium bromide/water mixture[J]. International Journal of Refrigeration, 2009, 32(4):627-637.

[2]Dai Yongqing, Lu Zheng. Lithium bromide absorption refrigeration and air conditioning technology Practical Handbook[M].Beijing: Machinery Industry Press.1999.

[3] Yu Guohe, Fei Weizhong. Experimental research on pool boiling heat transfer of water-lithium bromide solution at vacuum[J]. Journal of University of Shanghai for Science and Technology, 2001, 23(4):314-318.

[4]Chi Young Lee, Bong June Zhang, Kwang J. Kim. Influence of heated surfaces and fluids on pool boiling heat transfer[J]. Experimental Thermal and Fluid Science, 2014, 59:15-23.

[5]Xu Huibin, Song Xinnan, Ge Fenghua, Hu Zicheng. Experimental study of pool nucleate boiling heat transfer of aqueous $\mathrm{LiBr}$ solution at normal atmospheric pressure[J].Journal of Refrigeration, 2013,34(3):56-59.

[6]Jung-Yeul Jung, Eung Surk Kim, Youngsuk Nam, Yong Tae Kang. The study on the critical heat flux and pool boiling heat transfer coefficient of binary nanofluids ( $\mathrm{H} 2 \mathrm{O} / \mathrm{LiBr}+\mathrm{Al} 2 \mathrm{O} 3)[\mathrm{J}]$. International Journal of Refrigeration, 2013, 36(3):1056-1061.

[7]Song Xinnan, Gu Jiaqiang, Hu Zicheng,et al. An experiment on nucleate pool boiling heat transfer of aqueous surfactant solutions[J].Journal of Jiangsu University, 2010, 31(2):184-188.

[8]Moffat, R.J.Describing the uncertainties in experimental results[J]. Experimental Fluid and Thermal Science.1988, 1(1):3-17.

[9]Gao Hongtao, Hihara Eiji. Surface tension of LiBr a-queous solution with heat/mass transfer enhancement a-dditices[J]. Journal of Refrigeration, 2004, 25(3):5-8.

[10]S.Kulankara, K.E.Herold. Surface tension of aqueous lithium bromide with heat/mass transfer enhancement additives[J]. International Journal of Refrigeration, 2002, 25(3):383-389.

[11]S H Najibi, H Muller-steinhagen, M Jamialahmadi. Boiling and Nonboiling Heat Transfer to Electrolyte Solutions[J], Heat Transfer Engineering,1996,17(4):46-63.

[12]M Jamialahmadi, A Helalizadeh, H Muller Steinhagen. Pool boiling heat transfer to electrolyte solutions[J], International Journal of Heat and Mass Transfer,2004, 47(4):729-742. 